\title{
BONE DEFECTS OF THE FACIAL SKELETON - REPLACEMENT WITH BIOMATERIALS
}

\author{
Vítězslav Zbořil, Jindřich Pazdera, Vladislav Mot’ka \\ Clinic of Oral and Maxillofacial Surgery, Faculty of Medicine, Palacký University, 77515 Olomouc, Czech Republic
}

Received: April 21, 2003

Key words: Treatment of jaw-bone cysts / Cadaveric spongy bone / Effects of tetracycline

The authors report on their experience with bone defect treatment following surgery of jaw-bone cysts. This is based on the use of cadaveric ground spongiosis saturated with tetracycline and metronidazol solution. The study shows the above mentioned material is very suitable for bone defect therapy, and cost effective. The results were verified by clinical and X-ray examination.

\section{INTRODUCTION}

Odontogenic cysts are among the most frequent diseases of the jaw-bone. Their origin, mechanism of growth, as well as treatment related problems have been often discussed. What remains often problematic is healing of the bone defect after surgical removal of the cysts. This is a complicated process particularly after the removal of medium and large cysts requiring long-term postoperative care with local therapy. The final cure in the operated area is often problematic too. Moreover, there is the significant risk of pathological fracture of the weakened bone.

The precondition for bone defect healing is sufficient precipitate. However, the standard of blood may not be optimal in the process following the surgery. Filling the bone defect with various materials can substantially reduce its volume. A number of authors have been recommended that these cavities be filled with e.g. absorbable gelatin sponge, fibrin preparations, bone grafts or autologous, homologous or heterologous gristly grafts. At present, pharmaceutical companies compete in offering allogenic graft materials of various quality, which makes the best choice rather difficult, and especially considering that these materials are mostly very expensive. Moreover, after using some of them, allogenic material only in particular, the bone defect does not usually ossify. It fills only with inferior fibrous tissue.

Our study focuses on selection of material with properties that meet the highest biocompatibility criteria. At the same time, the material should be easy to handle and apply to bone defects; it should not only fill the cavity, but also support and speed up ossification following from its biological characteristics.

\section{MATERIALS AND METHODS}

In 1999, 85 patients were operated on for cysts of jaw-bones at our Department. In a group of 18 patients (7 female and 11 male), lyophilized ground cadaveric bone spongiosis saturated with tetracycline and metronidazol solution was used for bone defect reconstruction. No method of augmentation was used in the second (control group) of 11 patients (5 female and 6 male). The average age of the patients in the first group was 46 years, in the second, control group, 42 years.

Homologous cadaveric spongy tissue was used for augmentation of the bone defects. The material was supplied by the Tissue Bank of the University Hospital in Brno-Bohunice. Both the criteria and processing of this material fully meet European standards. The selection of donors depended on their personal and family history, on medical examination and on the results of serological tests. Tissue is not collected from donors suffering from hepatitis, active tuberculosis, uncured syphilis or who are HIV positive. The collection is also contraindicated in sepsis, systemic virus affection mycosis or any tumor disease aside from brain tumors, dermal basaliomas and recovered carcinomas in situ. The collection of bone grafts is carried out under sterile conditions. The quality control includes serological examination (HIV 1.2, HbsAg, HCV, syphilis), histological examination of the bone graft and sterility control which is carried out repeatedly in the course of collection and biological material processing. The bone grafts are used for transplantation only when all of the above mentioned examinations are negative. The spongiosis is harvested mechanically from condyles and heads of the long bones of the lower limbs.

In this study, in the first phase, fat was mechanically removed and a stream of warm water washed out bone marrow from the spongiosis. The final purification was carried out several times in $3 \%$ solution of hydrogen 
peroxide. Lyophilization (freezing to -80 degrees Celsius followed by sublimation of water in vacuum) was performed after drying up. The spongiosis was ground, sorted out, made into portions, and packed in double sealed PVC covers (Fig. 1). The size of single particles varied between 3-5 $\mathrm{mm}$ on average.

The spongiosis was processed under sterile conditions in the operating room. Sterility of the product was ensured by radiation ( $25 \mathrm{kGy}$ ). Shortly before application, the material was saturated with a solution of $0.25 \mathrm{~g}$ tetracycline and $0.25 \mathrm{~g}$ metronidazol and $5 \mathrm{~cm}^{3}$ of saline. The use of these preparations, especially tetracycline, was closely allied with the following healing of the bone wound filled with the cadaveric spongy bone.

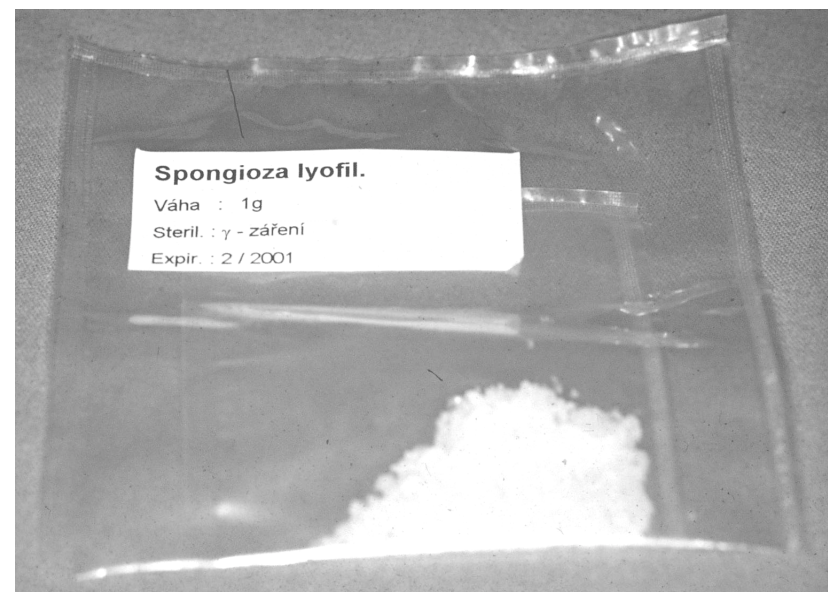

Fig. 1. Packet with the grinded cadaveric spongy bone.

\section{OPERATING PROCESS}

During the course of surgery (cystectomy, in some cases complemented by apex amputation of endodontically treated causal tooth or by its extraction) attention was paid to where the mucous section was to be performed, this should if possible be above a high-quality bone basis (Fig. 2). After cystectomy, the bone defect was filled with cadaveric spongy bone saturated with

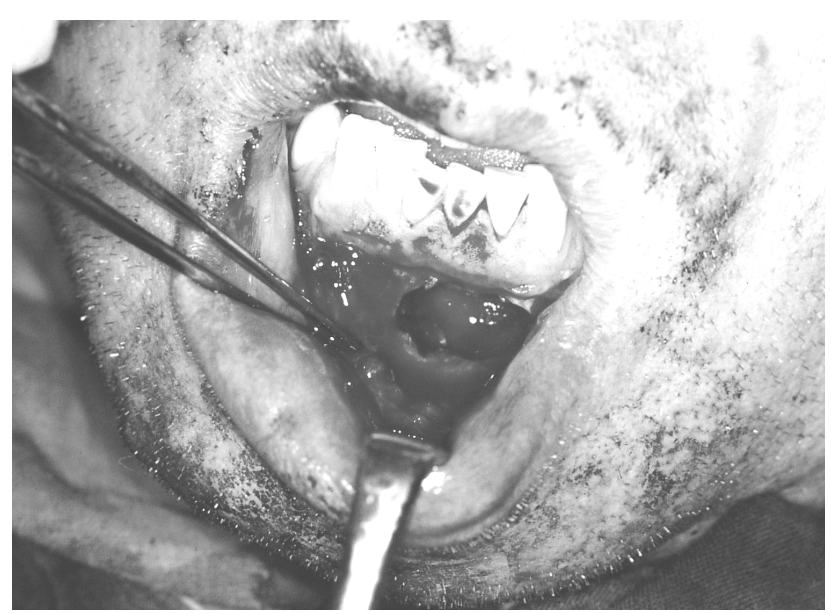

Fig. 2. Postoperative bone defect. tetracycline and metronidazol (Fig. 3). In case the wound in the bone was not bleeding enough, the bone transplant was saturated with venous blood collected from the patient's cubital vein. The wound was then covered with silk suture. Lincosamid antibiotics were applied systemically to prevent inflammatory complications.

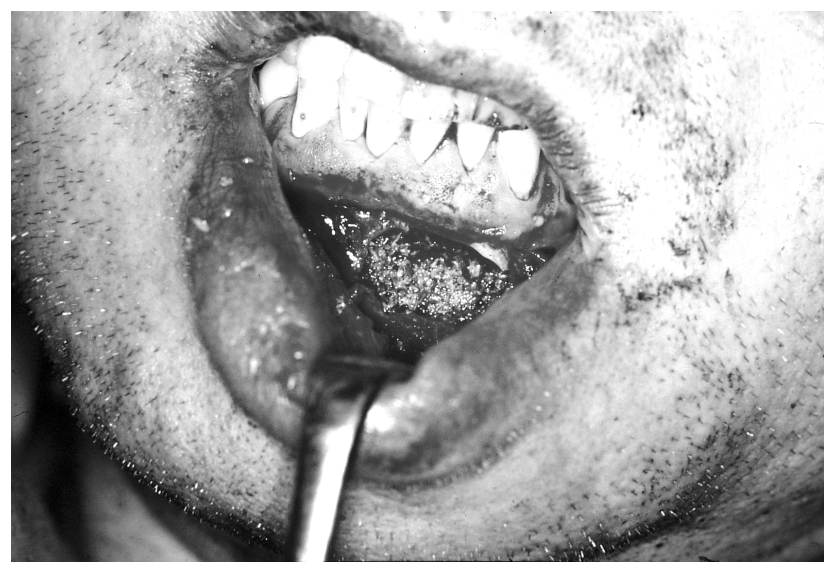

Fig. 3. Cadaveric spongy bone applied to the bone defect.

\section{RESULTS}

The size of the bone defects ranged from $1 \mathrm{~cm}^{3}$ to $20 \mathrm{~cm}^{3}$ (Fig. 4, 7, 10). The results of histopathological examination of the cystic bags (radicular and dentigerous cysts) were mostly identical with the clinical diagnosis. The course of treatment was monitored by clinical and X-ray examination just after the operation and then after 3 months in the first group and 6 months in the second group. Another examination was carried out 3 years later. This permitted analysis of only 9 patients from the first group and 11 patients from the second control group. This fulfilled the requirement of a 3-year interval between check-ups. Smooth course of healing without exsudation of the augmentative material from the bone defect, checked by X-ray examination, was set as the criterion for successful therapy.

Clinical examination of patients in the first group within the course of only 2 weeks postoperatively showed partial exsudation of the augmentative material only in 2 out of 18 patients (11\%) (Graph 1). This was observed in cases, where the suture was not situated straight above a high-quality bone basis or the mucous lobe could not be fastened enough to the neck of the tooth located in the immediate proximity of the operated area. These minor complications did not fundamentally influence the postoperative progress. Three months later, the X-ray examination shoewd vague margins of the postoperative defect providing evidence for successful healing. We failed to find any radiolucent zone around the graft that would demonstrate its demarcation or excretion. In some cases the margins of the original bone defect were already almost imperceptible (Fig. 5, 8). Bone treated in this way showed striking rapidity of 


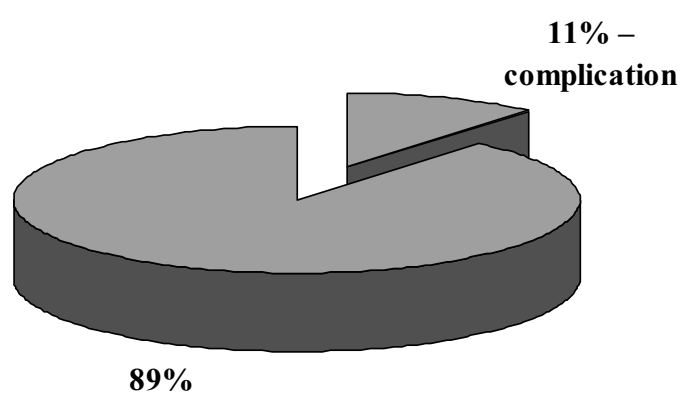

Graph 1. Results of treatment in 18 patients with augmentation.

healing, especially in cases where the distal root of the second lower molar reached the cyst area as well. Extraction of the tooth during the operation was necessary. Not only the bone defect but also the alveolus of the distal root was filled with augmentative material after the cystectomy. The alveolus of the mesial root healed in a standard way. The radiographs show the difference in ossification of both areas of the bone (Fig. 5). Three years later, X-ray examination showed the area of the original finding to be fully homogenous (Fig. 6, 9). None of our patients reported any discomfort.

In the second (control) group the healing complications (disintegration of the wound, genesis of fistula near the oral cavity, food retention in the bone defect) were noticed in 5 of 11 patients $(45 \%)$. These problems required long-term attendance of the operated area (lavage, ATB therapy) (Graph 2). X-ray examination provided evidence that the regenerative changes described in the first group 3 months after the surgery, appeared in the second group no earlier than after 6 months (Fig. 5, 8). After 3 years the differences demonstrated by X-ray examination tend to diminish. Neither groups of patients experienced any subjective or objective difficulties (Fig. 6, 9, 12).

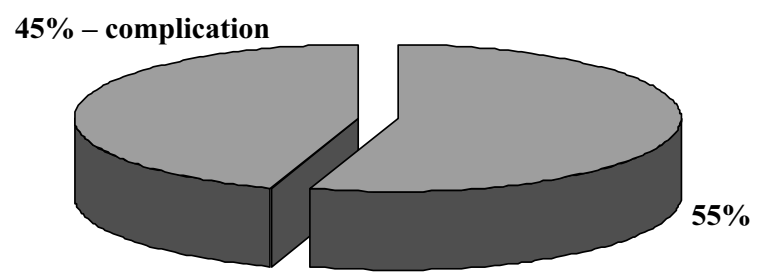

Graph 2. Results of treatment in 11 patients of the control group.

The fact that postoperative healing in the first group of patients showed no serious complications and successful and rapid ossification took place, even in cases where the augmentative material was partly excreted, speak clearly in favor of the proposed method. It is undeniable that 3 years after surgery the effect of treatment was identical in both groups. However, more rapid restitution of bone structures in patients in the first group justifies the use of augmentation materials.

\section{DISCUSSION}

Reduction of non-vital areas of the bone defect has often been recommended although. Selection of the most suitable augmentative material has remained question able. Pharmaceutical companies keep flooding the market with heterologous materials collected from pig bone tissue (BIO-GIDE) or with materials of bovine origin (BIO-OSS). They recommend covering these materials with absorbable or non-absorbable membranes after application to the defect. The results of the treatment are promising, especially in periodontology and dental implantology. However, this method does not seem to be satisfactory for the reconstruction of more extensive jaw-bone defects ${ }^{1}$. Moreover, these materials are very expensive and thus not accessible to all in practice. Hydroxyapatite-based (HA) preparations are cheaper. This material is used for total heightening of edentulous alveolar ridge ${ }^{2}$ or for bone defect filling. It is a non-absorbable allogenic material known as e.g. BASHA or BAS-O. Despite some authors recommend ations and claims for, good results, our experience with has not been the best: particles of implants were often excreted through the fistulas and a rather rigid scar infiltrated with HA fragments developed on the site of implantation instead of in the expected bone tissue.

Another method is bone defect reconstruction with hydroxyapatite harvested from natural corals ${ }^{3}$. Filling the bone defect with a placenta graft is, in our opinion, relatively unusual ${ }^{4}$.

In practice it is possible to use autologous material, e. g. from the iliac bone crest ${ }^{5}$. Unlike other authors ${ }^{6}$ we consider this unnecessarily burdening for the patient. Moreover, it may be connected with a risk of complications ${ }^{7}$.

The use of lyophilized cadaveric spongy bone tissue is a relatively frequent, comfortable and safe method for postoperative bone defect reconstruction. It is more successful than e. g. the use of absorbable gelatin sponge $^{8-11}$. Lyophilized material is easy to store and perioperative manipulation operation is very simple. Materials requiring storage in a deep-frozen state ${ }^{12}$ may not be always ready for immediate use and their storage is more demanding. We presumed that the spongy bone saturation with tetracycline solution would favorably affect healing of the bone wound. The antimicrobial effect of tetracycline bacteriostatically affects G- bacteria. Later, its inhibitive effect against collagenasis speeds up proper ossification of the postoperative bone defect $^{13-21}$. Metronidazol potentiates the antimicrobial effect of tetracycline and acts against most anaerobes. All these effects together speed up the bone wound healing. In concentrations used for our study, neither of the two preparations was contraindicated except for their possible antigenic effects in hypersensitive individuals.

The authors, using only demineralized, frozen spongiosis, confirm satisfactory healing of the defect after 6-9 months in children and 9-15 months in adults. 
In the first group of our patients the first signs of remodeling and ossification of the bone defects occurred as early as one month after the augmentation. The cost of lyophilized ground cadaveric spongy bone is compares very favourably with the above mentioned materials supplied by pharmaceutical companies.

\section{CONCLUSION}

The presented study deals with augmentation of postoperative jaw-bone defects using ground cadaveric spongy bone saturated with tetracycline and metronidazol solution. The success rate of the therapy was evaluated by clinical and X-ray examinations performed at 3 months' and 3 years' intervals after operation in the first group, 6 months' and 3 years' intervals after operation in the second (control) group.

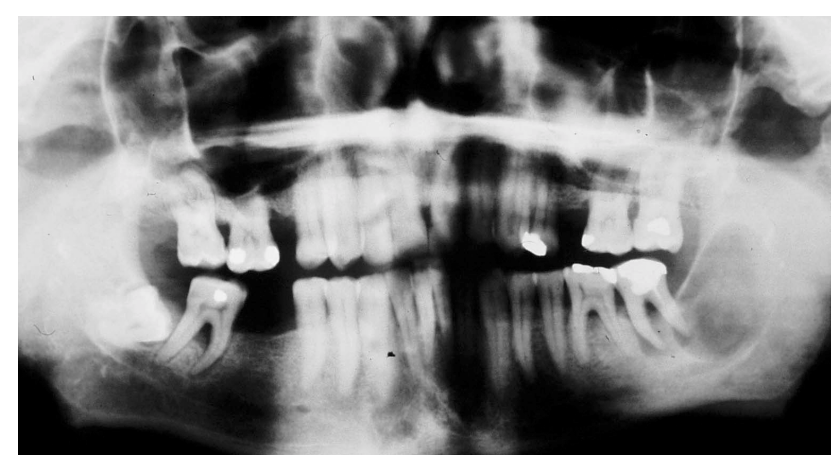

Fig. 4. Orthopantomograph showing the radicular cyst of the left mandibular angle (first patient of the $1^{\text {st }}$ group) - before operation.

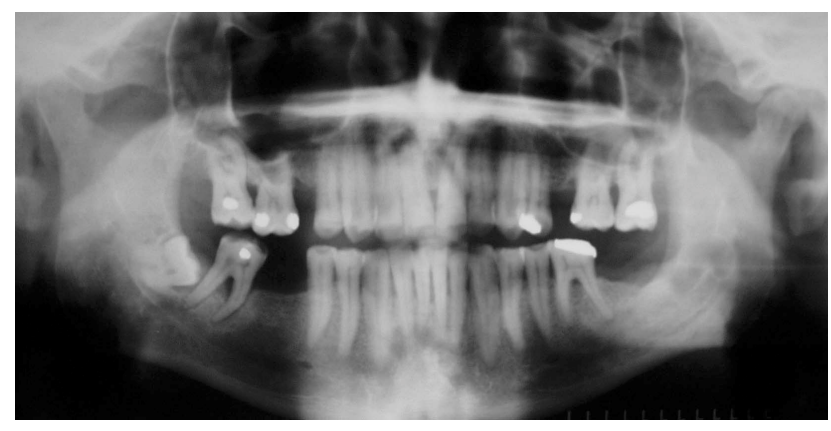

Fig. 6. Orthopantomograph showing the radicular cyst of the left mandibular angle (first patient of the $1^{\text {st }}$ group) -3 years after operation.
The results obtained so far indicate that the selected cadaveric spongy bone graft saturated with tetracycline and metronidazol not only fills the bone defect but at the same time speeds up its restoration. Minimal complications occurred (partial sequestration of the material in 2 patients) but even in these cases the defect ossified rapidly. The material is easy to apply and cost is effective. This rationale will certainly contribute to wide application of the material in jaw-bone surgery, including guided bone regeneration.

\section{ACKNOWLEDGEMENT}

This article was supported by grant of IGA/Ministry of Healthcare of the Czech Republic No 13901101.

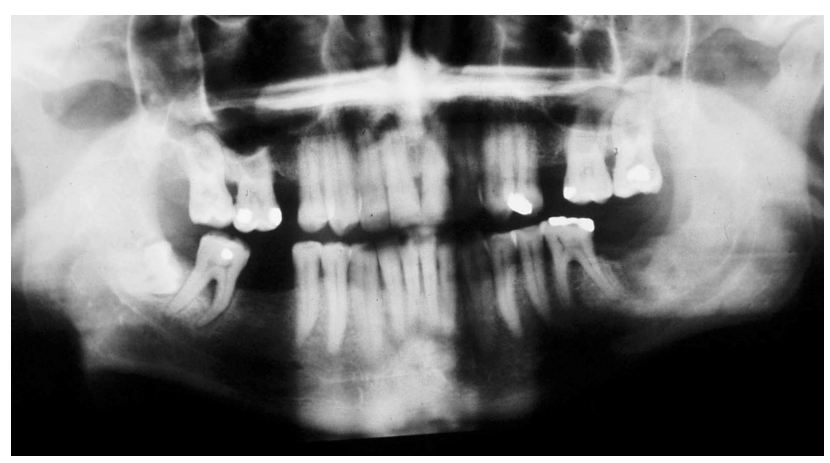

Fig. 5. Orthopantomograph showing the radicular cyst of the left mandibular angle (first patient of the $1^{\text {st }}$ group) - 3 months after operation.

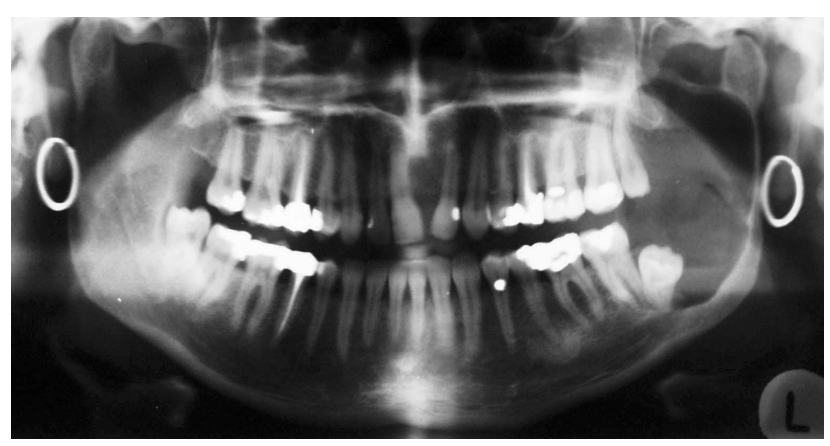

Fig. 7. Orthopantomograph showing the follicular cyst of the left mandibular angle and branch (second patient of the $1^{\text {st }}$ group) - before operation. 


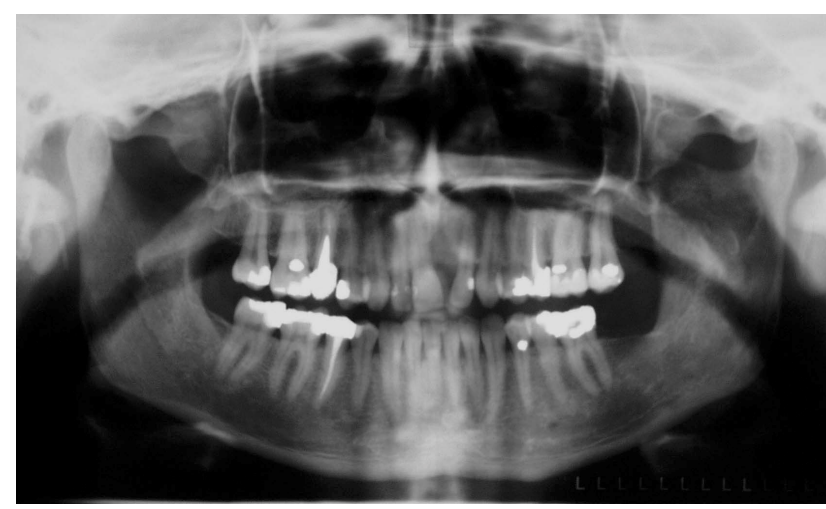

Fig. 8. Orthopantomograph showing the follicular cyst of the left mandibular angle and branch (second patient of the $1^{\text {st }}$ group) -3 months after operation.

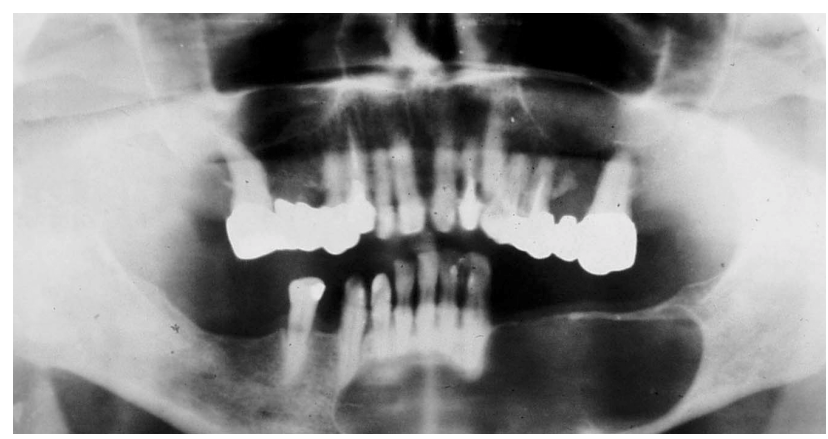

Fig. 10. Radiograph showing the radicular cyst of the mandible corpus (patient of the control group) before operation.

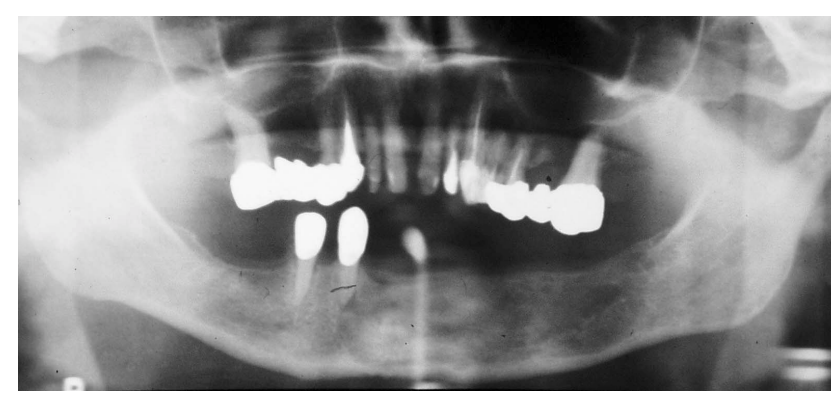

Fig. 12. Radiograph showing the radicular cyst of the mandible corpus (patient of the control group) 3 years after operation.

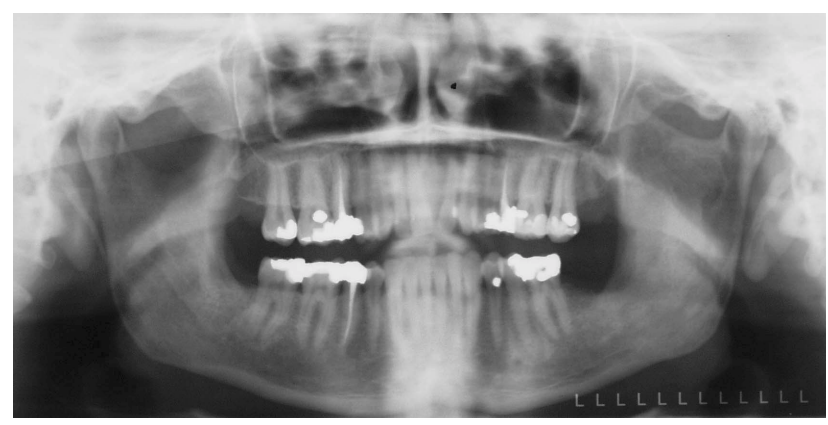

Fig. 9. Orthopantomograph showing the follicular cyst of the left mandibular angle and branch (second patient of the $1^{\text {st }}$ group) -3 years after operation.

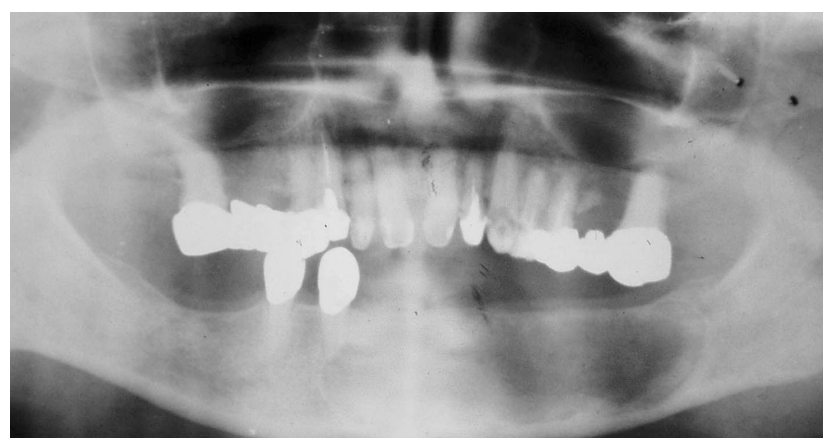

Fig. 11. Radiograph showing the radicular cyst of the mandible corpus (patient of the control group) 6 months after operation. 


\section{REFERENCES}

1. Babat O, Fontanesi RV (1996) Tissue Reconstruction Extends Indication for the Placement of osseointegrated Implants. The Global Forum 2, 8-9.

2. Procházková L, Štětka L. (1996) Augmentace atrofických čelistí hydroxylapatitem. Čes Stom 2, 60-5.

3. Holmes RE (1979) Bone regeneration within coralline hydroxyapatite implant. Plast Reconstr Surg 5, 626-33.

4. Efimov IV. (1993) The surgical treatment of periradicular cyst of the jaws. Stomatologiia 3, 26-7.

5. Štětka L, Machálka M. (1999) Rekonstrukce poúrazových defektů alveolárních výběžkủ čelisti kostními štěpy a dentálními implantáty. Čes Stomat 4, 123-6.

6. Sindet-Pedersen S, Enemark U. (1990) Reconstruction of alveolar clefts with mandibular or iliac crest bone grafts. A comparative study. J Oral Maxillofac Surg 5, 554-60.

7. Laurie SWW, Kaban LB, Mulliken JB. (1984) Donor site morbidity after harvesting rib and iliac bone. Plast Reconstr Surg 73, 933

8. Bodner L. (1998) Osseous regeneration in the jaws using demineralized allogenic bone implants. J Craniomaxillo fac Surg 2, $116-20$.

9. Bodner L. (1996) Effect of decalcified freeze-dried bone allograft on the healing of jaw defects after cyst enucleation. J Oral Maxollofac Surg 11, 1282-6.

10. Caplanis N. (1997) Effect of allogenic, freeze-dried, demineralized bone matrix on guided bone regeneration in supraalveolar periimplant defects in dogs. Int J Oral Maxillofac Implants 5, 634-42.

11. Goel SC. (1992) Allogenic decalbone in the repair of benign cystic lesion of bone. Int Orthop 2, 176-9.

12. Sethi A, Agarwal K, Sethi S, Kumar S, Marya SK, Tuli SM. (1993) Allograft in the treatment of benign cystic lesions of bone. Arch Orthop Trauma Surg 4, 167-70.
13. Hayrinen-Immonen R, Sorsa T, Pettila J, Konttinen Y. T., Teronen O, Malmstrom M. (1994) Effect of tetracyclines on collagenase activity in patients with recurrent aphthous ulcers. J Oral Pathol Med 6, 269-72.

14. Ingman T, Sorsa T, Konttinen YT, Liede K, Saari H, Lindy O, Suomalainen K. (1993) Salivary collagenase, elastase-and trypsinlike proteases as biochemical markers of periodontal tissue destruction in adult and localized juvenile periodontitis. Oral Microbiol Immunol 5, 298-305.

15. Ingman $T$, Sorsa $T$, Suomalainen $K$, Halinen S, Lindy O, Lauhio A, Saari H, KonttinenYT, Golob LM. (1993) Tetracycline inhibition and the cellular source of collagenase in gingival crevicular fluid in different periodontal diseases. A review article. J Periodontal 2, 82-8.

16. Maehara R, Hinode D, Terai H, Sato M, Nakamura R, Matsuda N, Tanaka T, Sugihara K. (1988) Inhibition of bacterial and mammalian collagenotic activities by tetracyclines. Nippon Shishubyo Gakkai Kaishi 1, 182-90.

17. Podhradský J, Číčelová A. (1995) Antioxidanty a parodontopatie. Čes Stomat 1, 17-9.

18. Podhradský J, Hlaváčiková D. (1993) Kyslíkové radikály v patogenéze parodontopatií. Čs Stomat 4, 206-8.

19. Podhradský J, Haščík J. (1993) Lipoperoxidácia v tkanive gingívy. Čs Stomat 5, 260-3.

20. Seymour RA, Heasman PA. (1995) Tetracyclines in the management of periodontal diseases. A review. J Clin Periodontol 1, 22-35.

21. Suomalainen K, Sorsa T, Golub LM, Ramamurthy N, Lee HM, Uitto VJ, Saari H., Konttinen YT. (1992) Specificity of the anticollagenase action of tetracyclines: relevance to their antiinflammatory potential. Antimicrob Agwnts Chemother 1, 227-9. 